\title{
ANNOUNCEMENTS
}

\author{
Society for Computers in Psychology \\ 15th Annual Meeting
}

The 15th annual meeting of the Society for Computers in Psychology will be held at the Boston Park Plaza Hotel, Boston, Massachusetts, November 21, 1985. This meeting features papers on applications of computers to all areas of psychology-experimental, clinical, and educationalwith the emphasis on on-line, laboratory applications. The deadline for papers is July 1, 1985.

For more information, contact Ira Fischler, Department of Psychology, University of Florida, Gainesville, Florida 32611 [(904)392-0605].

\section{Society for Computers in Psychology Student Paper Competition}

The Society for Computers in Psychology will continue to sponsor an award for the outstanding student paper submitted for presentation at the annual meeting. Although the primary emphasis of the conference is the use of computers in on-line, experimental applications, student papers in any area of the application of computers to psychology are welcome. Papers may be theoretical, experimental, or applied in approach. Eligibility is open to (1) work done by a student currently enrolled in undergraduate or graduate courses or (2) work done as part of a course, thesis, or other student research by a person who has graduated in 1985. All papers submitted for the conference (including multiply authored ones) in which the major contribution has been made by a student are eligible for the prize, and will be considered for presentation at the conference and subsequent publication. The winning paper will be presented at the 1985 conference, and the author will receive a complimentary 1-year membership in the conference, a complimentary 1-year subscription to Behavior Research Methods, Instruments, \& Computers, and a $\$ 50$ cash prize. Deadline for papers: July 1, 1985.

Eligible papers should be submitted in quadruplicate. A cover sheet should include the author's name, mailing address, telephone number, and academic affiliation, a 50-word abstract, and a note stating that the paper is to be considered for the student award. These materials should be sent to: Ira Fischler, Department of Psychology, University of Florida, Gainesville, FL 32611 [(904)392-0605]. 